\title{
DESIGN E MEDIAÇÃO TECNOLÓGICA: FORMAS DE PRODUÇÃO DE SUBJETIVIDADE
}

\author{
Barbara Jane Necyk \\ Pontifícia Universidade Católica do Rio de Janeiro \\ 07barbara@gmail.com \\ Jackeline Lima Farbiarz, Drạ \\ Pontifícia Universidade Católica do Rio de Janeiro \\ jackeline@puc-rio.br \\ Alexandre Farbiarz, Dr \\ Universidade Federal Fluminense \\ alexandre.farbiarz@gmail.com
}

Resumo: Este artigo está baseado em uma reflexão advinda de uma tese de doutorado quanto aos aspectos subjetivos da atividade de ensino em design mediada pela tecnologia digital e as possibilidades de posicionamento ideológico ante estas questões. As teorias de Guattari e Simondon aplicadas aos resultados de pesquisa definem a noção de que os objetos técnicos são uma realidade humana, assim como são parte da nossa subjetividade. É observado que a subjetividade se produz de forma coletiva e polifônica, assim como sua constituição é heterogênea. O trabalho de mediação constitutivo do objeto técnico faz com que a relação homemmáquina seja vista como um campo de aprimoramento, dentre outras possibilidades, pela introdução da tecnicidade em nosso mundo de significações. A dimensão ideológica da atividade de design entrecruzada pela possibilidade de desenvolvimento de novas formas subjetivas também é encaminhada por este artigo.

Palavras-chave: design; singularização; mediação; tecnologia; subjetividade.

\begin{abstract}
This article is based on a reflection that took place on a doctoral thesis about the subjective aspects of design teaching activity mediated by digital technology and the ideological positioning possibilities at these issues. Guattari and Simondon's theories applied to the research results define the notion that technical objects are a human reality, as well as part of our subjectivity. It is observed that subjectivity is collectively and polyphonicly produced, as well as its constitution is heterogeneous. The technical object constitutive mediation characteristic makes the man-machine relationship a field open to development, among other possibilities, by the introduction of technicality in our world of meanings. This article also refers to the design activity ideological dimension crossed by the possibility of developing new subjective forms.
\end{abstract}

Keywords: design; singling; mediation; technology; subjectivity. 


\section{INTRODUÇÃO}

Este artigo está baseado na pesquisa de doutorado intitulada Usos e sentidos de tecnologias digitais de informação e comunicação em contextos de ensinoaprendizagem no Design ${ }^{1}$ que se situou na confluência da questão tecnológica, aplicada ao ensino, com o caráter ideológico da atividade de Design.

O nosso cotidiano é permeado pelo uso de tecnologias digitais de informação e comunicação, fenômeno esse que também se insere no universo do ensino. A atividade de ensino em Design absorveu uma série de recursos informatizados nas últimas décadas. Com o objetivo de contribuir para a ampliação das possibilidades de se entender as formas de atuação dos designers na sociedade, a pesquisa mencionada fez um levantamento das dimensões subjetivas das atividades de ensino-aprendizagem através da mediação tecnológica. Partimos do seguinte pressuposto: ao utilizar determinada forma tecnológica em práticas em sala de aula, o professor está trabalhando com significados. A hipótese esteve centrada na observação de que a utilização de uma mídia material ou imaterial propicia percepções por parte de alunos e professores que configuram seu uso como uma representação em si. A pesquisa foi perpassada pela pergunta que questiona em que medida os professores de Design fazem uso de dimensões subjetivas advindas do uso de tecnologias digitais.

O objetivo principal da pesquisa foi contribuir na abertura de possibilidades de atuação de membros do campo do Design na sociedade tendo por pressuposto seu caráter ideológico. A abordagem empregada para o alcance desse objetivo foi a de levantar as dimensões subjetivas da atividade de ensino-aprendizagem em Design através de uma faceta específica: a mediação tecnológica. Para tanto, realizamos uma pesquisa em campo ${ }^{2}$ que teve como objetivo examinar estas questões. O contexto de observação de práticas de ensino-aprendizagem foi constituído por oito turmas de graduação em Design da PUC-Rio, no segundo semestre de 2012. A principal conclusão da pesquisa de campo foi que: o uso de tecnologias digitais de informação e comunicação no contexto pedagógico demonstrou ser uma força expressiva no campo do Design assim como uma representação do próprio campo.

A reflexão que encaminhamos neste artigo é oriunda deste enunciado, mas se estende por aspectos mais amplos. Neste texto, o foco se dá sobre a parte final da tese na qual uma reflexão sobre a questão da dimensão subjetiva advinda do uso de tecnologias digitais de informação e comunicação no ensino e na atividade de design em seu sentido amplo. O questionamento do posicionamento ideológico empregado na atividade de design também é aqui empreendido.

\footnotetext{
${ }^{1}$ A versão integral da tese de doutorado se encontra disponível em <http://www2.dbd.pucrio.br/pergamum/biblioteca/php/mostrateses.php?open=1\&arqtese=0912509_2013_Indice.html>. Acesso em 25 de maio de 2016.

${ }^{2} \mathrm{O}$ desenvolvimento e resultados da pesquisa de campo estruturada se encontram nos capítulos 4 e 5 da mencionada pesquisa de doutorado (acessar o link acima). Os mesmos desenvolvimento e resultados da pesquisa de campo estão resumidos no artigo Mediação tecnológica em contextos de ensinoaprendizagem: resultados da pesquisa de campo, publicado no P\&D Design 2014. Disponível em <http://www.proceedings.blucher.com.br/article-details/mediao-tecnolgica-em-contextos-de-ensinoaprendizagem-no-design-resultados-da-pesquisa-de-campo-12743>. Acesso em 25 de maio de 2016.
} 


\section{A SUBJETIVIDADE EM QUESTÃO}

Tendo por base o entendimento de que a subjetividade está articulada a processos sociais, optamos por seguir o caminho teórico aberto por autores que usam a noção de processos de subjetivação ou da produção de subjetividade, em lugar de uma concepção existente a priori de sujeito.

Dentre os vários autores utilizados para fundamentar a questão da subjetividade destacamos o filósofo francês Félix Guattari ${ }^{3}$. O conjunto teórico propiciado por Guattari foi utilizado nesta pesquisa: como principal fundamentação a definir a noção de subjetividade segundo uma matriz contemporânea; como pensamento que reconhece o lugar das máquinas no seio da subjetividade humana; como um incentivo a uma reapropriação dos componentes da subjetividade, produtora de processos de singularização.

Trabalhamos, também, na convergência do pensamento de Guattari com Simondon para entendimento da relação humana com os objetos técnicos. Realizamos o encontro teórico de Guattari e Bomfim para a constituição de uma postura ideológica associada à atividade de design.

\subsection{Da produção da subjetividade na contemporaneidade}

Guattari utiliza termos gerados a partir de uma concepção própria para veicular grande parte de seus conceitos. Para iniciarmos com o encaminhamento do pensamento do filósofo quanto à questão da subjetividade na contemporaneidade, precisamos, antes, esclarecer alguns de seus termos. Guattari conceitua dois tipos de máquinas (Guattari e Rolnik, 2005:288): as máquinas territorializadas (máquinas técnicas) e as máquinas desterritorializadas.

Quando o autor utiliza o termo "sistemas maquínicos", refere-se às duas concepções acima descritas. Ele se refere tanto às máquinas técnicas, assim como, às máquinas estéticas, às máquinas sociais, às máquinas teóricas, entre outras. Ao invés de funcionarem de forma isolada, as máquinas (em seu sentido amplo) funcionam por agregação ou por agenciamento, diz o autor. Guattari exemplifica como uma fábrica, uma máquina técnica, "está em interação com uma máquina social, uma máquina de formação, uma máquina de pesquisa, uma máquina comercial, etc" (Guattari e Rolnik, 2005:385). Guattari (1993:178) refere-se aos sistemas maquínicos como domínios que pertencem aos âmbitos técnico, biológico, semiótico, lógico e abstrato, entre outros.

Apesar de se unirem sob uma mesma sigla, a diferença marcante entre os dois tipos de máquinas citadas está no fato de que as máquinas desterritorializadas funcionam num nível de semiotização diferente das máquinas territorializadas. A máquina desterritorializada, para Guattari, pode ser entendida como "uma engrenagem de produção regida por forças que circulam e afetam o mundo" (Oliveira, 2005:58).

O termo "sistemas maquínicos" é utilizado pelo filósofo para marcar propositalmente a substituição da noção do sujeito como agência ${ }^{4}$ para a noção de

\footnotetext{
${ }^{3}$ Fazemos referência ao autor tendo por base seus textos individuais e as suas parcerias teóricas com Deleuze e, principalmente, com Rolnik.

${ }^{4} \mathrm{O}$ projeto da modernidade, datado do início do século XVI, trouxe em seu bojo a centralidade da subjetividade anexada à figura do indivíduo (Mancebo, 2002:101). O sujeito do lluminismo, assim denominado por Hall "estava baseado na concepção da pessoa humana como um indivíduo totalmente centrado, unificado e dotado das capacidades da razão, de consciência e de ação" (Hall, 2004:10-11).
} 
acoplamentos heterogêneos que produzem efeitos (Oliveira, 2005:58). Acreditamos que o termo "máquina" seja adequado para a transmissão da ideia de produção de efeitos, distinta da noção de uma coisa que é (esfera da ontologia). 0 termo também é apropriado para transparecer a ideia de categoria processual no lugar de uma categoria estrutural. Guattari é enfático em sugerir a dissociação dos conceitos de indivíduo e de subjetividade. "Para $\mathrm{mim}$, os indivíduos são o resultado de uma produção de massa. O indivíduo é serializado, registrado, modelado." (Guattari e Rolnik, 2005:40).

Separada da ideia de indivíduo, a subjetividade se dá em meio ao amplo campo dos processos sociais. A subjetividade não pode ficar circunscrita a ela mesma, pois as engrenagens sociais fazem com que continue se constituindo. Nesse sentido, o pensamento de Guattari se aproxima da concepção de Simondon ${ }^{5}$, que entende que o ser está em aberto, em permanente constituição. Não existiria, dessa forma, a possibilidade de uma subjetividade permanente, atrelada à figura do indivíduo. Em substituição à noção dada de sujeito, os processos de subjetivação se dão no mundo por intermédio de agenciamentos. Para Guattari, o termo "agenciamento" é entendido como uma noção mais ampla do que as noções de estrutura, sistema, forma, processo, montagem, entre outras. "Um agenciamento comporta componentes heterogêneos, tanto de ordem biológica, quanto social, maquínica, gnosiológica, imaginária" (Guattari e Rolnik, 2005:381). Para Guattari, a subjetividade é produzida por agenciamentos de enunciação. "Os processos de subjetivação ou de semiotização não são centrados em agentes individuais (no funcionamento de instâncias intrapsíquicas, egóicas, microssociais), nem em agentes grupais. Esses processos são duplamente descentrados" (Guattari e Rolnik, 2005:39).

O autor esclarece que os processos de subjetivação implicam no funcionamento de máquinas de expressão que possuem naturezas diversas (Guattari e Rolnik, 2005:39). As máquinas de expressão podem ser de natureza: extrapessoal, extraindividual (sistemas maquínicos, econômicos, sociais, tecnológicos, icônicos, ecológicos, etológicos, de mídia); infra-humana, infrapsíquica, infrapessoal (sistemas de percepção, de sensibilidade, de afeto, de desejo, de produção de ideias, sistemas de inibição e de automatismos, sistemas corporais, biológicos, etc).

Como visto, Guattari afirma que os componentes que concorrem para a produção de subjetividades são heterogêneos ${ }^{6}$. Estes componentes também são moldados pelas instituições disciplinares como a escola e a universidade. $\mathrm{O}$ autor acredita que a subjetividade é plural e polifônica e que não existe uma instância dominante de determinação que se sobrepuje às outras instâncias (Guattari, 1992:11). Dentre os múltiplos componentes que colaboram com os processos de subjetivação, Guattari reconhece a participação de tecnologias de informação e comunicação no âmago desses processos.

Para Guattari, a subjetividade deve ser separada da noção de indivíduo e de sujeito. Ele cita o "aprisionamento" vivido até os nossos dias em função do pensamento cartesiano (Descartes, 2001), que "colou" a ideia de sujeito, na forma de consciência subjetiva, à ideia de indivíduo.

${ }^{5}$ Para melhor compreensão do processo de individuação em Simondon, consultar o capítulo 2, item 2.1.4., da referida pesquisa de doutorado (acessar link na primeira nota de rodapé).

${ }^{6}$ Produção maquínica da subjetividade é outra expressão criada e usada pelo autor para transmitir a ideia de processualidade e de heterogeinidade mutante. 
Na pesquisa de campo, vimos como uma via de compreensão da subjetividade se constituiu de forma polifônica e heterogênea. Concluímos que as tecnologias digitais de informação e comunicação utilizadas em sala de aula são uma representação coletiva que diz respeito a valores circunscritos ao campo do Design, assim como a valores sociais mais amplos. O mundo das significações teria, dessa forma, diferentes instâncias de influência. Reelaboramos este enunciado para: ao carregar crenças e valores do campo, dentre outras instâncias de influência, o uso de tecnologias digitais de informação e comunicação no contexto pedagógico demonstrou ser uma força expressiva no campo do Design e uma representação do próprio campo do Design.

Poderíamos acrescentar que cada professor e que cada aluno vai processar essas representações coletivas de forma individual (representações individuais), nas situações em sala de aula, gerando a polifonia comentada por Guattari. Vimos por exemplo, como o uso de um mesmo dispositivo, o celular usado por alunos, pode ser tanto proibido quanto incentivado pelos professores.

Conforme Fróes (2010:110) "a utilização de um objeto técnico transforma o usuário em seu pensar/fazer, em função dos agenciamentos provocados por essa utilização". Para Bellei (2002), uma tecnologia jamais é apenas um instrumento de uso, mas um instrumento que também "usa" os seus usuários. "Somos sempre usados pelas coisas que usamos", diz Bellei (2002). Ao tomarmos contato com a teoria de Guattari, entendemos que as máquinas territorializadas, em associação com outros tipos de máquinas, configuram vetores de produção de subjetividade. Dessa forma, cada pessoa irá construir sua representação individual e coletiva engendrada pelos agenciamentos coletivos de enunciação dos sistemas maquínicos em operação.

Guattari encaminha o argumento de que se faz necessário constatar a presente condição de dependência de uma infinidade de sistemas maquínicos, dentre eles, as máquinas territorializadas. Como vimos anteriormente, toda atividade humana sente os efeitos de uso do meio tecnológico (Castells, 2009:108). Guattari (1993:177) amplia o escopo do fenômeno da penetrabilidade dos efeitos dos meios computacionais ao afirmar que todos os campos de opinião, de pensamento, de imagem, de afetos, de narratividade estão submetidos à influência da "assistência por computador", dos bancos de dados, da telemática, entre outros. Com efeito, pensamos que o uso de tecnologia digital de informação e comunicação no ensino pode ser entendido como um vetor de produção de subjetividade. Entendemos que os dispositivos tecnológicos são simultaneamente produtores de subjetividade, assim como efeito (resultado) dessa produção subjetiva. As situações observadas na pesquisa de campo confirmaram que o uso de objetos técnicos e as práticas associadas a esse uso funcionaram como vetores de produção de subjetividade.

Escóssia (1999:49) diz que o trabalho de mediação é constitutivo do objeto técnico e o argumento central de Simondon reside no fato de os objetos técnicos funcionarem como mediadores entre o homem e a natureza. Reelaboramos, então, a abordagem do pensamento que guiou a observação em sala de aula que se pautava em interações mediadas pela tecnologia digital na presença de no mínimo de duas pessoas. $O$ objeto técnico já trabalha numa relação direta de mediação entre o homem e o mundo. Os objetos técnicos seriam, segundo Latour (1991/1994), híbridos de natureza e cultura. Poderíamos acrescentar, ainda, que de maneira semelhante ao conceito de polifonia (Bahktin, 1981:3) - vozes plenas de valor contidas numa obra 
literária - os objetos técnicos, por vezes, "carregam vozes" - aspectos da subjetividade humana - com as quais interagimos numa relação homem/objeto técnico. Esse processo faz com que sejamos modificados, ou seja, o uso de um determinado objeto nos transforma em algo diferente do que éramos antes (Martin-Barbero, 2001).

Guattari (1993:177-178) baseia seu argumento de que a dupla ponte, do homem em relação à máquina e da máquina em direção ao homem, se tornará cada vez mais possível caso algumas condições sejam alcançadas. Em primeiro lugar, seria a não restrição das atuais máquinas informacionais e comunicacionais (as TDICs) na veiculação de conteúdos representativos, forma atual com a qual costumamos perceber os meios computacionais (computadores, laptops, etc). Guattari acha que essas máquinas devem concorrer da mesma forma para a confecção de novos agenciamentos de enunciação - individuais e/ou coletivos. Os objetos técnicos podem ser entendidos como geradores de significação. Encontramos apoio nesse argumento para a proposta elaborada por Simondon (2008:10-11): deixar de perceber os objetos técnicos como puros conjuntos de matéria desprovidos de significado. Em segundo lugar, Guattari propõe reconhecermos que todos os sistemas maquínicos - técnico, biológico, semiótico, lógico abstrato - "são o suporte, por si mesmos, de processos proto-subjetivos" os quais ele qualifica de subjetividade modular (Guattari, 1993:178).

Novamente, os pensamentos de Guattari e Simondon são convergentes quando afirmam que a intenção de desvio da máquina por parte do homem não faz sentido. Guattari afirma que as máquinas são formas hiperdesenvolvidas e hiperconcentradas de certos aspectos da nossa própria subjetividade (Guattari, 1993:177). Para Simondon (1958:12), “o que reside nas máquinas é a realidade humana, cristalizada em estruturas de funcionamento [...]". Conforme esclarece Simondon, existiria uma complementaridade entre o homem e os objetos técnicos. Entendemos que, de certa forma, "um carrega o outro": os objetos técnicos são derivados da subjetividade humana; para que um objeto técnico seja assimilado como tal, essa forma técnica deve preexistir na pessoa que o utiliza. Deleuze e Guattari (1977) afirmam que, antes de um instrumento ser técnico, ele é social, pois está inserido num quadro de referências administrativas, políticas, sociais, entre outras.

Por isso, pensamos que não há motivos para o homem esquivar-se da máquina. Ao nos alinharmos com o pensamento de que um objeto técnico possui uma dimensão social, consideramos que a usual oposição visualizada entre o homem e a máquina se desfaz. Acreditamos, contudo, fazer-se necessária uma recuperação de nosso relacionamento (ou entendimento) com os seres técnicos que, em muitas ocasiões, ainda nos parecem estranhos, apesar de serem uma parte de nós mesmos.

Recorremos ao pensamento de Heidegger, quando o filósofo afirma que o perigo da técnica é anterior à própria. Para o filósofo, o perigo reside na armação que é o modo moderno de o homem se posicionar em relação ao mundo. Na modernidade, e na instituição de uma subjetividade centrada na ideia de sujeito cartesiano, o homem passa a projetar um olhar (sujeito) sobre a natureza (objeto). A natureza passa a ser, para o homem, um conjunto de energias à sua disposição. Na atualidade, a tecnologia é basicamente utilizada nas seguintes formas: como instrumento da

\footnotetext{
${ }^{7}$ Para melhor compreensão da noção de armação em Heidegger, dentre outros conceitos associados ao pensamento de Heidegger, consultar o capítulo 2, itens 2.1.2. e 2.1.3., da referida pesquisa de doutorado (acessar link na primeira nota de rodapé).
} 
armação e como objeto da armação. Tudo leva a crer que, além de utilizarmos as máquinas como instrumentos para usufruto da natureza (do mundo), não conseguimos abordar a própria questão da técnica fora de uma postura de exploração máxima de recursos para a otimização de resultados. Heidegger (2007) nos alerta para o fato de que a armação impede o aparecer - o imperar da verdade. 0 homem subjugado à armação (essência da técnica moderna) é impelido ao desabrigar desafiante. Esse quadro parece se instaurar de forma generalizada na sociedade e, pensamos também, no campo do Design.

Afirmamos que, a despeito do fato de as máquinas serem muito presentes em nossas vidas, parece reinar um desconhecimento sobre as mesmas. "Enquanto representarmos a técnica como um instrumento, permaneceremos presos à vontade de dominá-la", diz Heidegger (2007) de maneira semelhante ao pensamento de Simondon quanto à nossa relação com os objetos técnicos. Acreditamos que a proposta de Simondon, que visa a reintrodução dos objetos técnicos no mundo das significações e no quadro dos valores e conceitos que participam da cultura, seja uma importante iniciativa para a melhoria da relação humana com a tecnicidade e para o (re)equilíbrio das forças sociais.

Fróes (2010:28) sugere que o reconhecimento de que as máquinas são vetores de produção de subjetividade seja o elo necessário para a consolidação do vínculo que falta entre a cultura e a técnica. Pensamos que esse seja um argumento bastante sólido e imaginamos que a reflexão em torno da questão possa trazer novas maneiras de se ver a tecnicidade contemporânea, assim como possa criar perspectivas para a mudança da atual situação na qual nos encontramos.

\subsection{Processos de singularização}

Tendo visto que a subjetividade se insere melhor numa categoria processual do que propriamente em algo que se detém (sujeito detentor de uma subjetividade), passamos a discutir uma de suas facetas mais marcantes. Tudo leva a crer que a subjetividade contemporânea parece estar intrinsecamente baseada em valores capitalistas de referência. Guattari acredita que exista uma "subjetividade capitalística que permeia todos os campos de expressão semiótica" (Guattari e Rolnik, 2005:30).

Guattari afirma que os modos de produção capitalista são caracterizados por formas de controle da subjetivação. O filósofo entende que "o capital ocupa-se da sujeição econômica, e a cultura, da sujeição simbólica" (Guattari e Rolnik, 2005:22). Em outras palavras, capital e cultura se inter-relacionam na formação de uma forma de subjetividade massificadora. Não por menos, Guattari identifica a cultura de massa como elemento fundamental da "produção de subjetividade capitalística" (Guattari e Rolnik, 2005:23).

Capitalismo Mundial Integrado é o termo utilizado por Guattari como alternativa ao termo globalização, que é, segundo ele, demasiadamente genérico. Além da esfera da representação, o Capitalismo Mundial Integrado atuaria no âmbito de uma modelização relacionada "aos comportamentos, à sensibilidade, à percepção, à memória, às relações sociais, às relações sexuais", dentre outras expressões da vida humana (Guattari e Rolnik, 2005:36). Em outras palavras, o Capitalismo Mundial Integrado modela e massifica todos os aspectos de nossa vida pessoal e coletiva segundo seus interesses e, principalmente, para sua automanutenção. 
No entanto, o filósofo enxerga a possibilidade de ações alternativas aos modelos hegemônicos de produção de subjetividade. As dinâmicas de produção de subjetividade capitalística poderiam ser desconstruídas através do desenvolvimento de modos de subjetivação singulares. O autor denomina estas dinâmicas como processos de singularização que são ao mesmo tempo formas de se recusar os modos de subjetividade pré-estabelecidos e pré-codificados e formas de construção de novos modos de sensibilidade. Estas novas formas sensíveis seriam geradoras de modos de criatividade e terminariam por verter uma subjetividade singular. Os processos de singularização são essencialmente dinâmicas que frustram os mecanismos de interiorização dos valores capitalistas (Guattari e Rolnik, 2005:55). Apesar de vivermos imersos em valores da sociedade globalizada, acreditamos ser possível afirmar novos valores a partir de um registro particular. Estas são possibilidades para o campo do design, assim para tantos outros campos de produção simbólica.

A despeito de vivermos em uma sociedade tecnologicamente avançada, a presente subjetividade hegemônica parece expressar uma série de valores conservadores. "A subjetividade permanece hoje massivamente controlada por dispositivos de poder e de saber que colocam as inovações técnicas, científicas e artísticas a serviço das mais retrógradas figuras da socialidade" (Guattari, 1993:191-192). Ainda assim, Guattari acredita na possibilidade da geração de diferentes formas subjetivas - formas processuais e singularizadoras.

Consideramos que, na atualidade, a questão da tecnologia e da subjetividade está em foco. $O$ destaque dado aos fatores subjetivos relacionados aos efeitos do uso das tecnologias digitais ganha corpo em função de sua intensa massificação através de uma mídia de massa (mass media) de alcance mundial. As tecnologias digitais de informação e comunicação ocupam importante parte nesse processo massificador, na forma de suporte tecnológico dos meios de comunicação de massa. Pensamos, contudo, que as mesmas tecnologias não são necessariamente instrumentos de dominação e opressão humana, assim como a crítica realizada pelos membros da Escola de Frankfurt fez acreditar ${ }^{8}$ em seu tempo. As tecnologias digitais parecem, entretanto, estar sendo principalmente utilizadas para confirmar a tendência já dominante de uma subjetividade capitalística. Pensamos que os efeitos do uso da tecnologia digital de informação e comunicação são determinados pela forma como a mesma é utilizada, ou seja, a potencialidade tecnológica pode se voltar tanto para um lado opressor e massificador quanto para um lado que exprima um viés libertário e criador de novas formas subjetivas ${ }^{9}$. Souza (2008:80) esclarece que, para Guattari, os aparatos tecnológicos não devem ser julgados como bons ou maus em sua essência. 0 julgamento deve levar em consideração os agenciamentos coletivos de enunciação

\footnotetext{
8 Para Adorno e Horkheimer, existe uma associação direta entre a tecnologia e a dominação ideológica, como se a primeira fosse uma manifestação da segunda. O argumento é baseado no fato de a tecnologia, produto da pesquisa científica, ser gerada essencialmente pela razão instrumental (Rose, 2012). Os frankfurtianos não produziram uma análise sobre a técnica moderna (ou a tecnologia), na qual essa esteja dissociada dos valores das elites dominantes.

${ }^{9}$ Para marcar posição quanto à questão da neutralidade da técnica, declaramos nos alinhar com os teóricos da abordagem ontogênica da técnica, como Simondon (1958) e Escóssia (1999). Acreditamos que a técnica não seja um instrumento neutro manipulável pelos homens, assim como acreditamos que objetos técnicos não tenham potência autônoma (Escóssia, 1999:49). Para além dessas dicotomias, pensamos que os objetos técnicos são mediadores entre o homem e a natureza, pois carregam em si algo da realidade humana.
} 
apropriados pelo uso dos sistemas maquínicos em operação nas situações sociais. Em outras palavras, devemos considerar os agenciamentos coletivos de enunciação que acompanham o uso tecnológico em seu contexto de aplicação, considerando as diversas "máquinas" a ele associadas, para melhor analisá-lo.

Seguimos com a linha de pensamento de Guattari. É através de movimentos alternativos - formas alternativas de reapropriação existencial e de autovalorização que o autor propõe que se empreendam meios para o alcance da era pós-mídia, assim denominada por ele para diferenciar tal cenário projetado da existente "massmidiatização" opressora. Apesar de parecer ser aparentemente utópico, acreditamos que o argumento do autor, centrado em sua crítica ao atual regime social regido por valores capitalistas, tenha fundamento e que suas ideias possam auxiliar na construção de perspectivas ante o cenário globalizado em que nos encontramos. Suas teorias nos interessam particularmente porque ele enxerga vias alternativas que surgem de dentro do próprio sistema, e porque compreende o preponderante papel das tecnologias computacionais, dentre outras instâncias, no engendramento de processos de singularização.

Ao mesmo tempo em que Guattari reconhece o uso das tecnologias inovadoras como instrumentos de controle da subjetividade, enxerga também, em seu seio, a possibilidade de rupturas com esse mesmo sistema. Mais precisamente, é justamente "no contexto das novas distribuições das cartas da produção da subjetividade informática e telemática que essa voz da autorreferência chegará a conquistar seu pleno regime" (Guattari, 1993:182). Articulamos, desta forma, o paradigma e o objetivo da pesquisa de doutorado mencionada à questão teórica fundamentada em Guattari.

Ao nos depararmos com as teorias de Guattari, o qual anuncia a possibilidade da reapropriação da subjetividade (distinta dos pacotes de subjetividade que nos são entregues constantemente) e a criação de processos de singularização, várias associações ocorreram em relação ao campo do Design. Acreditamos que além da recorrente e pertinente pergunta "O que há de singular no campo do Design?", deveríamos também indagar: "Como os membros do campo do Design podem contribuir na condução de processos de singularização?". Esta última pergunta nasce a partir do campo do Design e caminha para fora dele ao orientar nosso olhar para a sociedade em seu sentido amplo.

O paradigma da pesquisa de doutorado centrou-se no entendimento do Design como um campo de caráter ideológico ${ }^{10}$. Previamente, na pesquisa, tínhamos definido que uma atividade de caráter ideológico é aquela cujos efeitos legitimam, ou não, interesses hegemônicos.

Bomfim (1997) diz que o designer materializa, e, também diríamos, cria possibilidades de significação, de objetos de uso e sistemas de informação. $O$ autor também afirma que objetos e sistemas concebidos e produzidos por designers são, essencialmente, a materialização de noções e de valores sociais. Bomfim usa inclusive o verbo "moldar" ao afirmar que o designer "re-produziria realidades e moldaria indivíduos por intermédio de objetos que configura" (Bomfim, 1997:32). O autor não apenas evidencia o caráter ideológico da atividade de Design como também afirma

\footnotetext{
${ }^{10}$ Para melhor compreensão da noção do paradigma da pesquisa de doutorado mencionada, consultar o capítulo 4, item 4.1 (acessar link na primeira nota de rodapé).
} 
que a mesma é produtora de subjetividade. Ao reconhecermos o caráter ideológico do campo, reconhecemos, também, que este profissional deve assumir uma postura ideológica perante sua forma de atuação na sociedade.

Ao desempenhar projetos na atividade de Design, esse profissional encontra basicamente duas maneiras de atuação, conforme explica Bomfim (1999): uma que reproduz o modo social hegemônico e outra que trabalha nas brechas ou fissuras sociais, na proposição de novas formas de ação sobre a sociedade. Igualmente, Guattari visualiza duas posturas frente às formas subjetivas correntes na sociedade: uma postura de "relação de alienação e opressão" - a pessoa se submete à subjetividade da mesma forma como a recebeu; uma postura de "relação de expressão e de criação" - a pessoa se reapropria dos componentes da subjetividade, o que é chamado por Guattari de processo de singularização (Guattari e Rolnik, 2005:42).

Visualizamos um paralelo entre as definições de Bomfim e Guattari no que tange a uma postura de submissão e manutenção de modelos subjetivos, e outra postura na qual existe uma verdadeira criação em termos de novas formas subjetivas. Entendemos, assim como Guattari, que todo aquele cuja profissão consiste em se interessar pelo discurso do outro, como, de certa maneira, podemos classificar os professores e os designers, está numa encruzilhada política e micropolítica. Ou estas pessoas vão continuar a reproduzir os modelos que restringem os processos de singularização, ou vão operar no funcionamento desses processos, na medida das suas possibilidades e dos agenciamentos que consigam pôr para funcionar (Guattari e Rolnik, 2005:37). Desta forma, estabelecemos uma relação direta entre o "anúncio de novos caminhos" citado por Bomfim (1999:150) e os "processos de singularização" conceituados por Guattari (Guattari e Rolnik, 2005:42).

A título de organização do pensamento sobre a questão da tomada de consciência quanto à atuação de membros do Design, dividimos as iniciativas relativas aos processos de singularização em duas abordagens distintas: engendramento de processos de singularização que dizem respeito a questões do próprio campo do Design, como, por exemplo, as questões do ensino em Design; engendramento de processos de singularização que dizem respeito a projetos de Design para a sociedade em geral.

Embora sejam distintos, esses dois tipos de abordagem de processos de singularização teriam, consequentemente, alguma espécie de reverberação na sociedade. Essas são, por fim, possibilidades de se entender as formas de atuação de membros do Design na sociedade a partir de uma ótica na qual a questão subjetiva e o posicionamento ideológico do designer sejam levados em consideração, com ou sem a mediação tecnológica.

\section{CONCLUSÃO}

Entendemos que a subjetividade se produz de forma coletiva e é polifônica, assim como sua constituição é heterogênea. A subjetividade é produzida por diversas máquinas de expressão, dentre elas as máquinas territorializadas. Como diz Guattari, nossos campos de opinião, pensamento e afeto estão sob a influência dos meios informatizados. Concordamos com o autor quando ele visualiza que "uma voz de autorreferência" deverá sair do próprio seio dos meios informatizados. Além de serem afetos à tecnologia, os designers projetam objetos técnicos como smartphones, 
tablets, assim como projetam aplicativos e serviços para o meio online. Pensamos que os designers, em associação com outros profissionais, possuem um extenso campo de atuação no que diz respeito à criação de novas formas subjetivas no meio informatizado. Como desenvolver usos ou formas de relacionamento com os produtos e serviços digitais, é uma questão a ser pensada por designers. Acreditamos que uma via para a "inovação" não seja apenas fruto do uso de tecnologias avançadas, e sim uma apropriação particular da tecnologia na sua associação com agenciamentos coletivos de enunciação promotores de novas formas subjetivas - processos de singularização.

Para concluir, afirmamos que o uso de tecnologias digitais de informação e comunicação por designers, em seu sentido amplo, pode vir a ser um vetor de produção de uma nova perspectiva da subjetividade contemporânea.

\section{REFERÊNCIAS}

BAKHTIN, Mikhail. Problemas da poética de Dostoievski. Rio de Janeiro: Padrão, 1981.

BELLEI, Sérgio Luiz Prado. O livro, a literatura e o computador. São Paulo: EDUC; Florianópolis, 2002, 169 p.

BOMFIM, Gustavo Amarante. Coordenadas Cronológicas e cosmológicas como espaço das transformações formais. In: COUTO, Rita M. de S.; OLIVEIRA, Alfredo Jefferson. (orgs). Formas do Design: por uma metodologia interdisciplinar. Rio de Janeiro: 2AB; PUC-Rio, 1999, p. 137-155.

. Fundamentos de uma Teoria Transdisciplinar do Design: morfologia dos objetos de uso e sistemas de comunicação. In: Estudos em design V. 5, n. 2, dez. 1997. Rio de Janeiro: Associação de Ensino de Design do Brasil, p. 27-41.

CASTELLS, Manuel. A sociedade em rede. São Paulo: Paz e Terra, 2009.

DELEUZE, G; GUATTARI. Kafka: por uma literatura menor. Rio de Janeiro: Imago, 1977.

DESCARTES, René. Discurso do Método. São Paulo: Martins Fontes, 2001.

ESCOSSIA, Liliana de. Relação homem-técnica e processo de individuação. Aracaju: Editora UFS, 1999.

FRÓES, Jorge Rodrigues de Mendonça. Tecnologia e educação: das máquinas à técnica, uma abordagem segundo Gilbert Simondon. São Paulo: Blucher Acadêmico, 2010.

GUATTARI, Félix. Caosmose: um novo paradigma estético. Rio de Janeiro: Editora 34, 1992.

Da produção da Subjetividade. In: André Parente (org.). Imagem-máquina, a era das tecnologias. São Paulo: Editora 34, 1993.

GUATTARI, Félix; ROLNIK, Suely. Micropolitica: Cartografias do desejo. Petrópolis: Vozes, 2005.

HALL, Stuart. A identidade cultural na pós-modernidade. Rio de Janeiro: DP\&A, 2004. $104 \mathrm{p}$.

HEIDEGGER, Martin. A questão da técnica. In: Scientiae Studia, vol. $5 n^{\circ} 3$,São (2007) .Paulo jul./set. Disponível em <http://www.scielo.br/scielo.php?script=sci_ 
arttext \&pid=S1678-31662007000300006\&lng=pt\&nrm=iso\&tlng=pt>. Acesso em: 12 out. 2012.

LATOUR, Bruno. Jamais fomos modernos: ensaio de antropologia simétrica. Trad.: Carlos Irineu da Costa. Rio de Janeiro: Editora 34, 1991/1994.

MANCEBO, Deise. Modernidade e produção de subjetividades: breve percurso histórico. Psicol. cienc. prof., Brasília, v. 22, n. 1, mar. (2002).

$<$ http://pepsic.bvsalud.org/scielo.php?script=sci_arttext\&pid=S1414-98932002000100 011\&lng=pt\& nrm=iso>. Acesso em: $09 \mathrm{dez} .2011$.

MARTÍN-BARBERO, Jésus. Dos meios às mediações: comunicação cultura e hegemonia. Rio de Janeiro: Editora da UFRJ, 2001.

NECYK, Barbara Jane. Usos e sentidos de tecnologias digitais de informação e comunicação em contextos de ensino-aprendizagem no Design. Tese (Doutorado). Pontifícia Universidade Católica do Rio de Janeiro. 2013.

OLIVEIRA, R. M. Tecnologia e Subjetivação: a questão da agência (2005). Disponível em <http://www.scielo.br/pdf/psoc/v17n1/a08v17n1.pdf>. Acesso em 12 dez. 2012.

ROSE, Ricardo Ernesto. Tecnologia e dominação ideológica na Escola de Frankfurt. 11 fev. (2012). Disponível em <http://www.consciencia.org/tecnologia-e-dominacaoideologica-na-escola-de-frankfurt>. Acesso em: 31 jan. 2013.

SIMONDON, Gilbert. Du mode d'existence des objets techniques. Paris: AubierMontaigne, 2008.

L'individuation à la lumière des notions de forme et d'information. Paris:

Édition Jérôme Millon, 1958.

SOUZA, David Britto de. A Subjetividade Maquínica em Guattari. Dissertação de Mestrado. Centro de Humanidades Departamento de Psicologia. 2008. 